\title{
PENGEMBANGAN LKS MELALUI KEGIATAN IOI UNTUK MENILAI KOGNITIF DAN PERILAKU KONSERVASI SISWA SMA
}

\author{
Nur'azizah Prihatiningsih ${ }^{1 *}$, Aceng Ruyani ${ }^{1}$, Irwandi Ansyori ${ }^{1}$ \\ ${ }^{1}$ Program Studi Pendidikan Biologi, Fakultas Keguruan dan Ilmu Pendidikan, Universitas Bengkulu \\ e-mail : azizahningsih988@gmail.com,
}

\begin{abstract}
Abstrak
Jenis penelitian yang digunakan yaitu penelitian dan pengembangan (RnD). Masalah dalam penelitian ini yaitu: 1) bagaimana mengembangkan LKS konservasi kura-kura sehingga layak digunakan pada materi pembelajaran ekosistem, 2) apakah implementasi LKS hasil pengembangan melalui kegiatan IndoorOutdoor-Indoor (IOI) dapat meningkatkan kognitif siswa, 3) apakah implementasi LKS hasil pengembangan melalui kegiatan IOI dapat meningkatkan kecenderungan berprilaku konservasi bagi siswa. Penelitian ini bertujuan untuk: 1) menganalisis kelayakan pengembangan LKS konservasi kura-kura pada materi pembelajaran ekosistem, 2) menilai kognitif siswa melalui kegiatan IOI menggunakan LKS konservasi kurakura Sumatera dan 3) menilai perilaku konservasi siswa melalui kegiatan IOI menggunakan LKS konservasi kura-kura Sumatera. Penelitian ini menggunakan metode kuantitatif kualitatif deskriptif. Pembelajaran dengan menggunakan strategi indoor-outdoor menggunakan LKS konservasi kura-kura Sumatera. Untuk menilai kognitif siswa menggunakan tes tertulis berupa pretest dan posttest, sedangkan untuk menilai perilaku konservasi siswa menggunakan angket prilaku konservasi. Pembelajaran indoor dilaksanakan di sekolah dan pembelajaran outdoor dilaksanakan ditempat konservasi kura-kura Sumatera di Universitas Bengkulu. Uji kelayakan bahan ajar LKS berupa aspek materi dan aspek kebahasaan, dengan persentase 80$88 \%$ memiliki kriteria "sangat layak" untuk di uji cobakan dilapangan. Ketuntasan belajar klasikal (kognitif) dengan persentase $15,3 \%$, tidak tuntas secara klasikal. Ketidaktuntasan dikarenakan penyampaian konsep materi oleh peneliti dirasa kurang dan peserta didik tidak menyimak pembelajaran dengan baik. Kecenderungan berperilaku konservasi awal siswa dengan persentase 18,43\% dan prilaku konservasi akhir siswa dengan persentase $22,71 \%$, mengalami peningkatan $4,28 \%$.
\end{abstract}

Kata kunci: Kura-kura Sumatera, Research and Development (RnD), Lembar Kerja Siswa (LKS), IndoorOutdoor

\begin{abstract}
The type of research used is research and development (RnD). The problems in this research are: 1 ) how to develop LKS of turtle conservation so it is feasible to be used in ecosystem learning material 2) whether LKS implementation of development result through Indoor-Outdoor-Indoor (IOI) activity can improve student's cognitive 3) The results of development through IOI activities can improve the tendency of conservative behavior for students. This study aims to: 1) analyze the feasibility of developing LKS conservation of turtles on ecosystem learning materials, 2) assessing cognitive students through IOI activities using LKS conservation of Sumatran turtles and 3) assessing student conservation behavior through IOI activities using LKS conservation turtle- Turtle Sumatra. This research uses quantitative qualitative descriptive method. Learning using indoor-outdoor strategy using LKS conservation of Sumatran turtles. To assess students' cognitive using written test in the form of pretest and posttest, while to assess student conservation behavior using conservation behavior questionnaire. Indoor learning is carried out in schools and outdoor learning takes place in the conservation area of Sumatran turtles at Bengkulu University. Feasibility study of LKS materials in the form of material and linguistic aspects, with percentage of $80-88 \%$ have "very feasible" criteria to be tested in the field. Exhaustiveness classical learning (cognitive) with the percentage of $15.3 \%$, not completely classical. The non-completion due to the submission of the concept of the material by researchers felt less and learners do not listen to learning well. The tendency of students' initial conservation behavior with the percentage of $18.43 \%$ and the final conservation behavior of students with the percentage of $22.71 \%$, an increase of $4.28 \%$
\end{abstract}

Keywords: Sumatran turtle, Research and Development (RnD), Student Worksheet (LKS), Indoor-Outdoor 


\section{PENDAHULUAN}

Pendidikan adalah suatu usaha sadar dan terencana untuk mewujudkan suasana belajar dan proses pembelajaran agar peserta didik dapat aktif mengembangkan potensinya. Sekolah merupakan lembaga formal yang berfungsi membantu khususnya orang tua dalam memberikan pendidikan kepada anak-anak mereka (Widiyatmoko, 2014). Pendidikan Nasional berupaya mengembangkan kemampuan dan membentuk watak serta peradaban bangsa yang bermartabat dalam rangka mencerdaskan kehidupan bangsa dan bertujuan untuk berkembangnya potensi peserta didik agar menjadi manusia yang beriman dan bertakwa kepada Tuhan Yang Maha Esa, berakhlak mulia, sehat, berilmu, cakap, kreatif, mandiri dan menjadi warga negara yang demokratis serta bertanggung jawab (Trianto, 2012).

Pendidikan konservasi adalah program yang bertujuan untuk memberikan pengetahuan kepada banyak orang agar lebih sadar dan lebih perhatian dalam melestarikan lingkungan. melindungi, dan memanfaatkan sumberdaya hayati secara bijaksana dan berkelanjutan. Program Pendidikan konservasi dapat diadakan dalam berbagai bentuk, termasuk melalui pendidikan formal dan non-formal (Zukmadini, 2017).

Indonesia merupakan salah satu negara terkaya di dunia dalam hal keanekaragaman hayati. Pulau di Indonesia mampu menampung sekitar $12-13 \%$ dari semua keanekaragaman hayati yang ada di dunia, namun pada saat ini tingkat keanekaragaman hayati di Indonesia mulai menurun akibat pencemaran lingkungan, perdagangan ilegal, dan lain sebagainya. Hal ini akan meyebabkan suatu spesies dalam keadaan rawan atau hampir punah. Untuk mempertahankan keberadaan jenis-jenis tersebut, Indonesia membutuhkan pengetahuan yang dapat melindungi dan mempertahankan keanekaragaman kekayaan alam dari satu generasi ke generasi berikutnya. Selain dilindungi hendaknya juga dapat dimanfaatkan misalnya sebagai objek dan tujuan wisata alam (Iskandar, 2000).

Provinsi Bengkulu memiliki banyak ragam fauna, salah satunya adalah kurakura. Kura-kura adalah hewan reptil yang mudah dikenal karena karapaks yang membungkus badannya, yang bertindak sebagai perisai untuk menghadapi ancaman musuh dan yang menonjol keluar hanya kaki, kepala dan ekornya (Kursini dan Yazid, 2005).

Berdasarkan angket yang telah dibagikan di SMAN 09 Kota Bengkulu pada tanggal 17 Januari 2017, dan diisi oleh kelas $X$ IPA 2, dari 29 peserta didik yang mengikuti tes di kelas X IPA 2 hanya beberapa peserta didik saja yang mengenal kura-kura. Berdasarkan hasil wawancara dengan peserta didik, kebanyakan dari mereka melihat kura-kura diacara salah satu stasiun televisi, dan juga ada beberapa peserta didik yang melihat kura-kura dipasar, kura-kura itu untuk diperjual belikan. Dari data angket yang telah disebarkan dan diisi oleh siswa kelas $X$ SMAN 9 Kota Bengkulu, tampak bahwa hanya $26,52 \%$ yang sudah pernah melihat kura-kura, dan hanya $12,31 \%$.

Berdasarkan hasil penelitian yang pernah dilakukan sebelumnya, yang dilakukan oleh tim Partnerships for Enhanced Engagement in Research (PEER) PROJECT S2 Pendidikan IPA Universitas Bengkulu dengan menggunakan Lembar Kerja Siswa (LKS) yang ada dimodul "Pendidikan Konservasi Kura-kura Sumatera" pada pembelajaran tingkat SMA 
yang pernah dilaksanakan di SMAN 8 Kota Bengkulu pada tahun 2016, ada aspek yang memang belum diukur, yaitu perilaku konservasi dari peserta didik itu sendiri, serta dalam mengukur perilaku konservasi, juga bisa menilai kognitif dari peserta didik tersebut.

Berdasarkan hasil wawancara dengan guru SMAN 9 Kota Bengkulu pada bulan januari 2017, sekolah belum memiliki LKS tentang konservasi kura-kura. Peneliti juga belum mengenal kura-kura, maka dari itu dirasa perlu bagi peneliti untuk mempelajari kura-kura.

Maka dari itu, peneliti ingin mengembangkan LKS yang akan dirancang secara sistematis dan menarik perhatian siswa, untuk menilai kognitif siswa dan perilaku konservasi siswa. Karena menurut Arsyad (2009), salah satu keunggulan yang dimiliki LKS adalah dapat mengembangkan kemampuan kognitif siswa dalam menelaah fakta yang ada. Dalam penelitian ini, menggunakan kegiatan Indoor-OutdoorIndoor (IOI) yang akan dilakukan di sekolah dan juga di tempat konservasi kura-kura di Universitas Bengkulu.

\section{METODE}

Metode yang digunakan pada penelitian ini adalah metode penelitian dan pengembangan atau Research and Development (R\&D). Metode R\&D adalah metode penelitian digunakan untuk menghasilkan produk tertentu dan menguji keefektifan produk tersebut. Metode R\&D merupakan pendekatan untuk menghasilkan produk baru atau penyempurnaan produk yang telah ada, yang terdiri dari sepuluh langkah (Sugiyono, 2016). Namun dalam penelitian ini dilakukan langkah-langkah penggunaan metode Research and Development (R\&D) yang dilakukan hanya sampai langkah ke enam, yaitu uji coba produk pada skala kecil (potensi masalah, pengumpulan data, desain produk, validasi desain, revisi desain dan uji coba produk).

Penelitian ini dilakukan di dua tempat, pada kegiatan indoor dilaksanakan di ruangan kelas X IPA 2 dan pada kegiatan outdoor dilaksanakan di Taman Pintar Universitas Bengkulu. Penelitian ini melibatkan 34 siswa SMA kelas X.

Teknik pengumpulan data yang dilakukan menggunakan angket dengan instrumen lembar angket, untuk menilai perilaku konservasi. Untuk menilai kognitif siswa menggunakan tes tertulis dengan instrumen lembar tes berupa pretest dan posttest. Uji kelayakan LKS dengan validasi, instrumen yang digunakan yaitu lembar validasi.

\section{HASIL DAN PEMBAHASAN}

\section{Hasil Uji Kelayakan LKS oleh Validator}

Dari hasil uji kelayakan LKS yang divalidasi oleh 3 dosen Pendidikan Biologi dan 3 guru Biologi SMA sebagai validator. Data mengenai uji kelayakan LKS dapat dilihat pada Tabel 1.

Tabel 1. Hasil perhitungan uji kelayakan LKS dari validator

\begin{tabular}{|c|c|c|c|c|}
\hline \multirow[b]{2}{*}{ No } & & Aspek & & \\
\hline & Validator & $\begin{array}{c}\text { yang } \\
\text { diamati }\end{array}$ & Persentase & Kriteria \\
\hline \multirow[t]{3}{*}{1} & Dosen & Aspek & $88 \%$ & Sangat \\
\hline & Biologi & materi & & layak \\
\hline & & $\begin{array}{l}\text { Aspek } \\
\text { kebahasaan }\end{array}$ & $81,3 \%$ & $\begin{array}{l}\text { Sangat } \\
\text { layak }\end{array}$ \\
\hline \multirow[t]{3}{*}{2} & Guru & Aspek & $82,5 \%$ & Sangat \\
\hline & Biologi & materi & & layak \\
\hline & & $\begin{array}{l}\text { Aspek } \\
\text { kebahasaan }\end{array}$ & $80 \%$ & $\begin{array}{l}\text { Sangat } \\
\text { layak }\end{array}$ \\
\hline
\end{tabular}

Pengembangan LKS yang disusun memuat delapan unsur, yang terdiri dari 
cover, KD yang akan dicapai, tujuan pembelajaran, konsep/materi, prosedur kerja berupa alat dan bahan serta cara kerja, hasil pengamatan yang berupa gambar ataupun tabel, pertanyaan dan kesimpulan.

Hasil penelitian menunjukan bahwa LKS yang dibuat sudah memenuhi kriteria dan layak diuji cobakan. Demi penyempurnaan LKS, adanya sedikit revisi yang sudah disarankan oleh validator, saran dari para validator terlampir pada Tabel 2.

Menurut Salirawati (2013), LKS yang baik yaitu menggunakan struktur kalimat yang jelas, menggunakan kalimat yang sederhana dan pendek, gambar yang baik untuk LKS adalah yang dapat menyampaikan pesan/ isi dari gambar tersebut secara efektif kepada pengguna LKS. Penampilan adalah sangat penting dalam LKS. Pertama-tama siswa akan tertarik pada penampilan LKS, bukan isinya.

Apabila suatu LKS ditampilkan dengan penuh kata-kata, kemudian ada pertanyaan-pertanyaan yang harus dijawab oleh siswa, hal ini menimbulkan kesan jenuh sehingga membosankan dan tidak menarik. Apabila ditampilkan dengan gambar saja, itu tidak mungkin karena pesan / isinya tidak akan sampai. Jadi yang baik adalah LKS yang memiliki kombinasi antara gambar dan tulisan.
Tabel 2. Saran validator terhadap perbaikan LKS

\begin{tabular}{|c|c|c|}
\hline No & Validator & Saran perbaikan \\
\hline 1 & Dosen biologi & $\begin{array}{l}\text { 1. Setiap penggunaan teori pada LKS harus } \\
\text { menyertakan referensi } \\
\text { 2. Pada bagian pertanyaan harus menyertakan } \\
\text { pertanyaan yang menuntut siswa untuk } \\
\text { berfikir (menganalisis) } \\
\text { 3. Ada beberapa kalimat yang sulit dipahami, } \\
\text { diperbaiki sehingga siswa mampumenjawab } \\
\text { pertanyaan tersebut } \\
\text { 4. Grafis (gambar) dibuat semenarik mungkin }\end{array}$ \\
\hline 2 & Guru biologi & $\begin{array}{l}\text { 1. Mohon ditinjau ulang untuk nomor } \\
\text { kompetensi dasar (KD) dan ada beberapa } \\
\text { notasi dan tulisan yang belum lazim } \\
\text { digunakan terutama pada keterangan } \\
\text { gambar, untuk notasi dan simbol mohon } \\
\text { disertakan aturan yang sesuai dengan SI } \\
\text { Nomor KD tolong ditinjau kembali sesuai } \\
\text { tidak dengan silabus terbaru }\end{array}$ \\
\hline
\end{tabular}

\section{Hasil Respon Siswa terhadap LKS}

Hasil angket keterbacaan LKS yang dibagikan kepada 15 sampel peserta didik dari 34 peserta didik pada kelas X IPA 2, yang terbagi menjadi empat aspek penilaian pada Tabel 3.

Tabel 3. Respon siswa terhadap LKS

\begin{tabular}{llc}
\hline \multicolumn{1}{c}{ Aspek yang diamati } & \multicolumn{1}{c}{ Nilai } & \multicolumn{1}{c}{ Kriteria } \\
\hline Pembelajaran dalam & 12,9 & Sangat layak \\
LKS & & \\
Tampilan LKS & 13,2 & Sangat layak \\
Penggunaan LKS & 8,7 & Sangat layak \\
Materi dalam LKS & 8,7 & Sangat layak \\
\hline
\end{tabular}

\section{Hasil Pengimplementasian LKS Melalui Kegiatan IOI}

Dari hasil analisis data validasi oleh dosen dan guru biologi serta angket keterbacaan respon siswa, maka LKS Konservasi Kura-kura Sumatera, sangat layak diimplementasikan kepada peserta didik.

Setelah LKS dinyatakan sangat layak di uji cobakan dilapangan oleh validator, peneliti melakukan penelitian untuk menilai kognitif dan perilaku konservasi melalui kegiatan Indoor-Outdoor-Indoor (IOI). Kegiatan indoor dilaksanakan di ruang kelas $X$ IPA 2 SMAN 9 Kota Bengkulu, sedangkan 
untuk kegiatan outdoor dilaksanakan di Taman Pintar dan Green Chimestry Universitas Bengkulu yang merupakan area konservasi kura-kura.

Pada kegiatan indoor 1, siswa diberikan soal tes (pretest) berupa tes tertulis dalam bentuk essai untuk mengukur pengetahuan awal siswa, dan siswa juga diberikan angket perilaku konservasi. Siswa diberikan materi awal tentang ekosistem dan kegiatan pada outdoor yang akan dilaksanakan keesokan harinya.

Pada kegiatan outdoor siswa diajak mengenal ekosistem kolam di Taman Pintar, diajak mengenal kura-kura, mengukur komponen abiotik ekosistem, mengamati komponen biotik ekosistem, mempelajari morfologi kura-kura. Pada kegiatan indoor 2, kegiatan yang dilakukan mereview pembelajaran pada indoor 1 dan juga outdoor. Siswa diberikan posttest dan juga angket perilaku konservasi untuk mengukur tingkat pemahaman siswa.Data mengenai kognitif siswa dapat dilihat pada Tabel 4.

Tabel 4. Hasil kognitif siswa

\begin{tabular}{lc}
\hline Uraian & Hasil analisis \\
\hline Jumlah seluruh siswa & 34 \\
Jumlah siswa yang mengikuti & 29 \\
pretest & \\
Jumlah siswa yang mengikuti & 26 \\
postest & \\
Jumlah siswa yang tuntas & 4 \\
Rentang nilai siswa & $0-100$ \\
Nilai sempurna peritem soal & 20 \\
Nilai rata-rata pretest & 43,97 \\
Nilai rata-rata postest & 52,5 \\
Nilai Kriteria Ketuntasan Minimal & 75 \\
(KKM) & \\
Ketuntasan belajar klasikal & $15,3 \%$ \\
\hline Kesimpulan & Tidak tuntas \\
\hline Adapun nilai LKS & pada \\
Tabelompok & siswa di
\end{tabular}

Tabel 5. Nilai LKS siswa

\begin{tabular}{|l|c|c|c|c|c|c|c|c|c|c|}
\hline Kelompok & \multicolumn{2}{|c|}{ l } & \multicolumn{2}{|c|}{2} & \multicolumn{2}{|c|}{3} & \multicolumn{2}{|c|}{4} & \multicolumn{2}{|c|}{5} \\
\hline Kegiatan & I & $\mathbf{0}$ & I & $\mathbf{0}$ & I & $\mathbf{0}$ & I & 0 & I & 0 \\
\hline Nilai & 55 & 58 & 50 & 59 & 75 & 69 & 50 & 50 & 53 & 85 \\
\hline Rerata & \multicolumn{2}{|c|}{56,5} & \multicolumn{10}{|c|}{54,5} & 72 & \multicolumn{2}{|c|}{50} & \multicolumn{2}{|c|}{69} \\
\hline Rerata & \multicolumn{10}{|c|}{60} \\
\hline
\end{tabular}

Setelah diimplementasikan LKS Konservasi Kura-kura Sumatera mengalami peningkatan tidak secara keseluruhan, hanya $8,8 \%$, akan tetapi tidak tuntas secara klasikal. Seorang siswa dinyatakan tuntas jika skor melebihi 75 dari skor maksimal 100. dari nilai KKM yang telah ditentukan (75) hanya 4 siswa atau 15,3\% yang nilainya diatas KKM. Menurut Murtopo (2013), hal yang menyebabkan nilai tidak tuntas dikarenakan, perilaku siswa di dalam kelas juga bisa berpengaruh pada ketidaktuntasan. Karena bagaimanapun seorang guru tidak hanya mengajar saja, namun juga mendidik. Jika di dalam kelas seorang siswa sering mempunyai kelakuan atau sikap yang tidak bagus dan mengganggu proses KBM, maka bisa juga berpengaruh kepada nilainya.

Penilaian LKS kelompok siswa, melalui kegiatan IOI, dengan nilai rata-rata 60,4 dari 5 kelompok siswa. Nilai LKS kelompok kurang dari kategori KKM yang telah ditentukan (75). Menurut Aini (2015), adapun faktor-faktor yang memengaruhi hasil belajar ada 3, yaitu faktor internal, faktor eksternal dan faktor pendekatan belajar. Kendala yang dihadapi pada saat KBM dikelas X IPA 2, yaitu:

1) Faktor internal, yang berasal dari dalam diri siswa sendiri, terbagi menjadi dua yaitu aspek fisiologis (jasmani) dan aspek psikologis (rohani). Menurut Aini (2015), aspek fisiologi yaitu kondisi umum jasmani dan tonus (tegangan otot) yang menandai tingkat kebugaran organ-organ tubuh dan sendi-sendinya, 
dapat mempengaruhi semangat dan intensitas siswa dalam mengikuti pelajaran. Sedangkan aspek psikologis yaitu tingkat kecerdasan siswa, sikap siswa, bakat siswa, minat siswa dan motivasi siswa.

2) Faktor eksternal, menurut Aini (2015), faktor eksternal juga dibagi menjadi dua, yaitu faktor lingkungan sosial sekolah dan faktor lingkungan nonsosial. faktor lingkungan sosial sekolah, seperti para guru, para staf sekolah dan teman-teman sekelas dapat mempengaruhi semangat belajar seorang siswa, sedangkan faktor lingkungan nonsosial, seperti gedung sekolah dan letaknya, rumah tempat tinggal keluarga siswa dan letaknya, alat-alat belajar, keadaan cuaca dan waktu belajar yang digunakan siswa.

3) Faktor pendekatan belajar, dapat dipahami sebagai segala cara atau strategi yang digunakan siswa dalam menunjang keefektifan dan efisiensi proses pembelajaran materi tertentu. Faktor pendekatan belajar juga berpengaruh terhadap taraf keberasilan proses pembelajaran siswa tersebut.

Perilaku konservasi siswa terhadap kura-kura mengalami peningkatan dari $18,43 \%$ menjadi $22,71 \%$, dapat dilihat pada Tabel 6.
Tabel 6. Kecenderungan berprilaku konservasi kura-kura bagi siswa

\begin{tabular}{|c|c|}
\hline \multicolumn{2}{|c|}{ Angket kecenderungan berprilaku konservasi } \\
\hline Jumlah siswa (awal) & 29 siswa \\
\hline Persentase awal & $18,43 \%$ \\
\hline Rata-rata angket awal (1-2) & 1,47 \\
\hline Jumlah siswa (akhir) & 26 siswa \\
\hline Akhir & $22,71 \%$ \\
\hline Rata-rata angket akhir (1-2) & 1,82 \\
\hline Kesimpulan & Meningkat $\mathbf{4 , 2 8} \%$ \\
\cline { 2 - 2 } & Meningkat $\mathbf{0 , 3 5}$ \\
\hline
\end{tabular}

Selain menilai kognitif, peneliti juga menilai perilaku konservasi kura-kura bagi siswa. Perilaku konservasi kura-kura bagi siswa, mengalami peningkatan sebesar 4,28 \%. Pada saat pemberian angket diawal sebelum diimplementasikannya LKS konservasi kura-kura Sumatera, persentase prilaku konservasi kura-kura bagi siswa hanya 18,43 \% karena angket diberikan sebelum LKS digunakan melalui kegiatan IOI, namun setelah diimplementasikannya LKS konservasi kura-kura Sumatera, prilaku konservasi siswa mengalami peningkatan, menjadi 22,71 \% artinya melalui kegiatan IOI, LKS efektif untuk meningkatkan kecenderungan berprilaku konservasi kurakura bagi siswa.

Menurut Ruyani (2009), sikap berarti personal segera apresiasi dan kesadaran sebagai respon terhadap kondisi lingkungan tertentu dalam bentuk rangsangan sosial dan/ atau fisik. Dipercaya secara luas bahwa pengetahuan merupakan faktor penting dalam mengembangkan beberapa sikap dan kemudian sikap yang diinternalisasi akan dinyatakan kemudian dalam perilaku tertentu. Tingkat apresiasi dan kesadaran lingkungan ini adalah proses internalisasi psikologis yang perlu diikuti dengan penegakan berturut-turut dan berulang. 


\section{PENUTUP}

\section{Simpulan}

Berdasarkan tujuan penelitian, diperoleh kesimpulan sebagai berikut:

1) Dari hasil perhitungan validasi LKS pada materi ekosistem, LKS konservasi kurakura Sumatera sangat layak diujicoba dengan persentase $80-88 \%$.

2) Hasil perhitungan pretest dan posttest yang telah dilakukan oleh siswa, melalui kegiatan IOI, LKS konservasi kura-kura Sumatera tidak efektif untuk meningkatkan kognitif siswa, dengan nilai KKM hanya 15,3 \% (tidak tuntas secara klasikal).

3) Hasil pengisian angket kecenderungan berprilaku konservasi siswa, melalui kegiatan IOI, LKS konservasi kura-kura Sumatera efektif untuk meningkatkan kecenderungan berprilaku konservasi kura-kura bagi siswa dari 18,43\% menjadi $22,71 \%$ dengan rentang ratarata angket dari 1,47 menjadi 1,82 .

\section{Saran}

Adapun saran berdasarkan kelemahan dan kekurangan pada waktu penelitian, adalah:

1) Bagi peneliti selanjutnya harus sudah terlatih dalam proses pembelajaran, misalnya mengikuti kegiatan PPL atau pernah mengajar didalam kelas agar konsep tersampaikan kepada siswa. Pada penelitian yang telah dilakukan, kognitif tidak tuntas secara klasikal, dikarenakan tidak adanya kegiatan PPL dan peneliti hanya mengikuti kegiatan magang, yang tidak mewajibkan mengajar didalam kelas.

2) LKS ini dapat digunakan untuk penelitian tindakan kelas untuk meningkatkan sikap ilmiah siswa dengan kegiatan pembelajaran outdoor.
3) LKS ini dapat dikembangkan lagi untuk penelitian dan pengembangan dengan subbab materi yang berbeda, seperti, interaksi antar komponen ekosistem dan pada materi keanekaragaman hayati.

\section{DAFTAR PUSTAKA}

Aini, Dina Rizki. 2015. Faktor-faktor Yang Menyebabkan Ketidaktuntasan Nilai Anak (Studi di SDN 22 Kecamatan Pontianak Barat). Skripsi diterbitkan. Pontianak: UNTAN (jurmafis.untan.ac.id/index.php/sosi odev/article/viewFile/640/pdf_17 diakses 19 april 2017)

Iskandar, D.T.. 2000. Kura-kura \& Buaya Indonesia \& Papua Nugini. Bandung: PAL Media Citra

Kursini, M.D dan Yazid, M. 2005. Kura-kura Asia dalam Krisis dalam Warta Herpetofauna edisi 3. Bogor: ITB

Kursini, M.D dan Yazid, M. 2005. Kura-kura Asia dalam Krisis dalam Warta Herpetofauna edisi 3. Bogor: ITB

Ruyani, A. 2009. Integrating the Message of Turtle Corservation into a Science Teaching Plan for Elementary School in Bengkulu City (http://www.asianturtlenetwork.org/library /reports papers/Integrating message of $\mathrm{t}$ urtle conservation into science teaching i n Bengkulu Indonesia Jan 2009.html diakses 14 Mei 2017)

Salirawati, D. 2013. Penyusunan dan Kegunaan LKS Dalam Proses Pembelajaran. 
(staffnew.uny.ac.id/upload diakses 3 mei 2017)

Sugiyono. 2016. Metode Penelitian Kuantitatif Kualitatif dan $R$ \& $D$. Bandung: Alfabeta

Trianto. 2012. Model Pembelajaran Terpadu. Jakarta: Bumi Aksara

Widiyatmoko, A. 2014. Implementasi Modul Pembelajaran IPA Tema "Konservasi" Untuk Menumbuhkan Karakter Siswa. Makalah disajikan dalam Seminar Nasional Konservasi dan Kualitas Pendidikan 2014, Semarang, 12 Mei

Zukmadini, A.Y, Wiryono, Aceng $\mathrm{R}$ dan Catherine M. 2017. Pengetahuan Konservasi Pada Siswa SMA dengan Pembelajaran Indoor-Outdoor Menggunakan Modul Pendidikan Konservasi Kura-kura. Dipresentasikan Pada SEMIRATA Wilayah Barat Bidang MIPA- Jambi 